\title{
OXIDATION OF BENZALDEHYDE BY QUINOXALINIUM DICHROMATE
}

\author{
K. ANBARASU ${ }^{1 *}$ and N. GEETHA ${ }^{2}$
}

1. Department of Chemistry, Arignar Anna Govt. Arts College, Musiri - 621 211, Tamilnadu. arasu007@gmail.com

2. Department of Chemistry, Paavaai Group of Institutions, Namakkal - 637 018, Tamilnadu.

\section{ABSTRACT} gee_vika@rediffmail.com

The kinetics and mechanism of oxidation of benzaldehyde by quinoxalinium dichromate has been studied in the presence of perchloric acid in $70 \%$ acetic acid - water medium. The reaction follows first order with respect to benzaldehyde, quinoxalinium dichromate and fractional order with respect to perchloric acid. There is no effect on the reaction rate with increase in ionic strength of the medium by adding sodium perchlorate. The rate of reaction increases with increase in the percentage of acetic acid. The reaction does not induce the polymerization with acrylonitrile. The rate of reaction decreases with increase in the concentration of manganoussulphate. The thermodynamic and activation parameters have been calculated and a probable mechanism has been proposed.

\section{Keywords}

Oxidation, Kinetics, Mechanism, Benzaldehyde, Quinoxalinium dichromate

\section{Academic Discipline And Sub-Disciplines}

Chemistry

\section{SUBJECT CLASSIFICATION}

Physical Organic Chemistry

\section{TYPE (METHOD/APPROACH)}

Oxidation Kinetics

\section{INTRODUCTION}

Quinoxalinium dichromate $\left(\mathrm{C}_{8} \mathrm{H}_{6} \mathrm{~N}_{2} \mathrm{H}_{2}\right) \mathrm{Cr}_{2} \mathrm{O}_{7}$ (QxDC) has been used in the oxidation of many organic substrates. QxDC[1] is reported to be neutral and mild oxidant for selective oxidation reactions and readily separable from the desired products. The probable structure of quinoxalinium dichromate is given below,

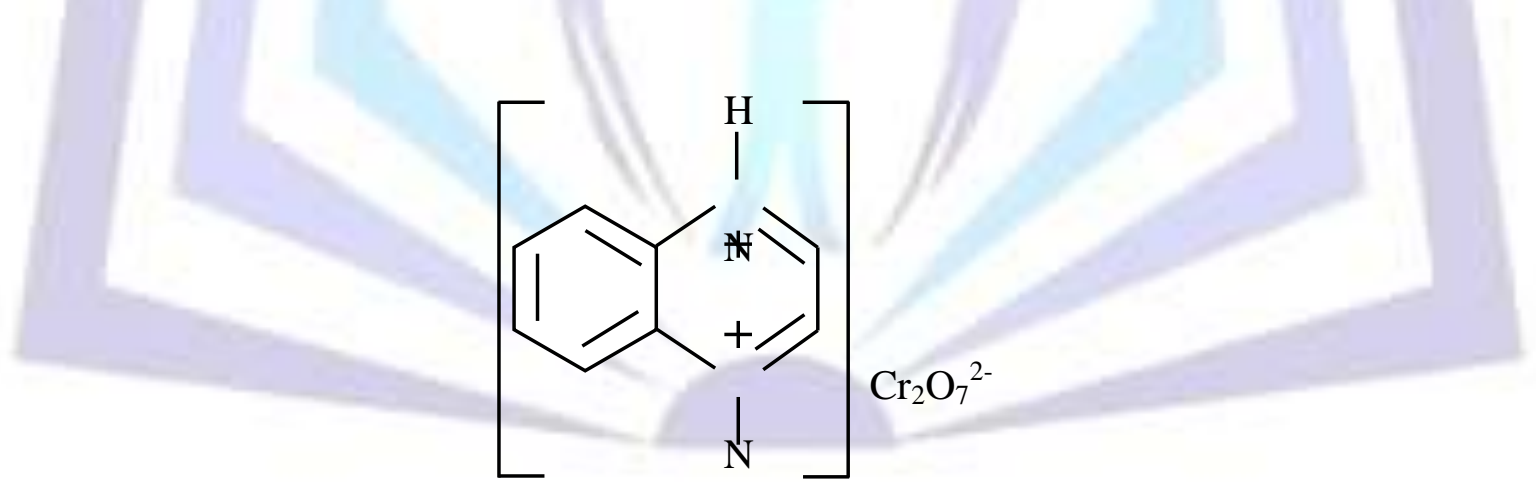

$\mathrm{H}$

Quinoxalinium dichromate

Kinetics of oxidation of some organic substrates[2-5] by quinoxalinium dichromate has also been reported. The kinetics and mechanism of oxidation of oxidation of benzaldehyde by various oxidants have been reported[6-19]. In this paper, we report the mechanistic aspects of the oxidation of benzaldehydes by quinoxalinium dichromate.

\section{EXPERIMENTAL}

\section{Preparation of Quinoxalinium dichromate}

A solution of $26.4 \mathrm{~g}$ of quinoxaline $(0.2 \mathrm{~mol})$ in $60 \mathrm{cc}$ of water was slowly added to a cooled solution of $21.0 \mathrm{~g}$ of chromic acid $(0.2 \mathrm{~mol})$ in $20 \mathrm{cc}$ of water. After $30 \mathrm{~min}$, the reaction mixture was diluted with $40 \mathrm{cc}$ of acetone, cooled to $-15^{\circ} \mathrm{C}$, and 


\section{Volume ... N u m ber...}

Journal of Advances in Chemistry the orange solid was filtered, washed with acetone and dried in vaccuo. The compound melted at $115^{\circ} \mathrm{C}$ (literature m.p. $115-116^{\circ} \mathrm{C}$ ) and further analyzed through spectral data. Its purity was checked by estimating $\mathrm{Cr}(\mathrm{VI})$ iodometrically.

Benzaldehyde (AnalaR) was purchased from Aldrich and used as such. Acetic acid was refluxed over chromium trioxide containing acetic anhydride for $6 \mathrm{~h}$ and then fractionated. Other chemicals were of AnalaR grade. Double distilled water was used throughout the kinetic study.

\section{Kinetic measurements}

The pseudo-first order conditions were attained by keeping a large excess (10 fold excess or greater) of the benzaldehyde with respect to quinoxalinium dichromate. The reactions were carried out at constant temperature $( \pm 0.3 \mathrm{~K})$ using thermostat and were followed up to $75 \%$ conversion by monitoring the decrease in [QxDC] at $470 \mathrm{~nm}$ on a spectrophotometer. The pseudo-first order rate constant $k_{1}$ was evaluated from the linear plots of log absorbance versus time. Duplicate kinetic runs showed that the rates were reproducible within $\pm 3 \%$.

\section{Product analysis}

The reaction mixture with excess of oxidant over the substrate was added. Then, it was slightly warmed and kept at room temperature for $24 \mathrm{~h}$. It was extracted with ether and the product was obtained and dried with anhydrous sodium sulphate. The product was identified by checking its physical constants (m.p. $120^{\circ} \mathrm{C}$ ). It was dissolved with ethanol and tlc analysis was done with benzoic acid and standard sample of benzoic acid as a reference.

\section{RESULTS AND DISCUSSION}

The reaction was studied under different experimental conditions in the presence of acetic acid-water $(70 \% v / v)$ as solvent medium. At a constant temperature, the rate increased steadily on increasing the concentration of the substrate as shown in Table 1. The linear plot of log $\mathrm{k}$ against log [substrate] with a slope (1.07) of unity clearly indicates that the reaction has unit order dependence on the concentration of the substrate. At fixed $\left[\mathrm{H}^{+}\right]$with [substrate] in excess, the plot of log absorbance against time was linear indicating first order with respect to QxDC.

Table 1. Rate Constants for the Oxidation of Benzaldehyde by QxDC at $313 \mathrm{~K}$

\begin{tabular}{|c|c|c|c|}
\hline $\begin{array}{c}\text { [Benzaldehyde] } 10^{2} \\
\mathrm{~mol} \mathrm{dm}^{-3}\end{array}$ & $\begin{array}{c}{[\mathrm{QxDC}] 10^{3}} \\
\mathrm{~mol} \mathrm{dm}^{-3}\end{array}$ & $\begin{array}{l}{\left[\mathrm{H}^{+}\right] 10} \\
m o l d m^{-3}\end{array}$ & $\begin{array}{c}\mathrm{k}_{1} 10^{4} \\
s^{-1}\end{array}$ \\
\hline 4.0 & 2.0 & 3.0 & 7.69 \\
\hline 5.0 & 2.0 & 3.0 & 9.36 \\
\hline 6.0 & 2.0 & 3.0 & 11.19 \\
\hline 7.0 & 2.0 & 3.0 & 13.68 \\
\hline 8.0 & 2.0 & 3.0 & 16.11 \\
\hline 5.0 & 1.0 & 3.0 & 9.42 \\
\hline 5.0 & 2.0 & 3.0 & 9.36 \\
\hline 5.0 & 3.0 & 3.0 & 9.44 \\
\hline 5.0 & 4.0 & 3.0 & 9.34 \\
\hline 5.0 & 2.0 & 1.5 & 7.00 \\
\hline 5.0 & 2.0 & 3.0 & 9.36 \\
\hline 5.0 & 2.0 & 4.5 & 12.85 \\
\hline 5.0 & 2.0 & 6.0 & 14.35 \\
\hline
\end{tabular}

$\%$ AcOH:Water $=70: 30$

The effect of added $\mathrm{H}^{+}$ion on the pseudo-first order rate constant was studied by adding $\mathrm{HClO}_{4}$ in the region of $0.15-0.60$ M. The rate of reaction increased with increase the concentration of $\mathrm{HClO}_{4}$. The plot of log $\mathrm{k}$ against log $\left[\mathrm{H}^{+}\right]$gave a straight line with slope 0.54 (Fig. 1) indicating that fractional order with respect to hydrogen ion concentration. The rate of reaction increased with the increase in the percentage of acetic acid (Table 2), the plot of log $\mathrm{k}_{1}$ against 1/D was found to be linear with a positive slope (Fig. 2), which was confirmed the ion-dipole interaction [20-22] in the rate determining step. 
Journal of Advances in Chemistry

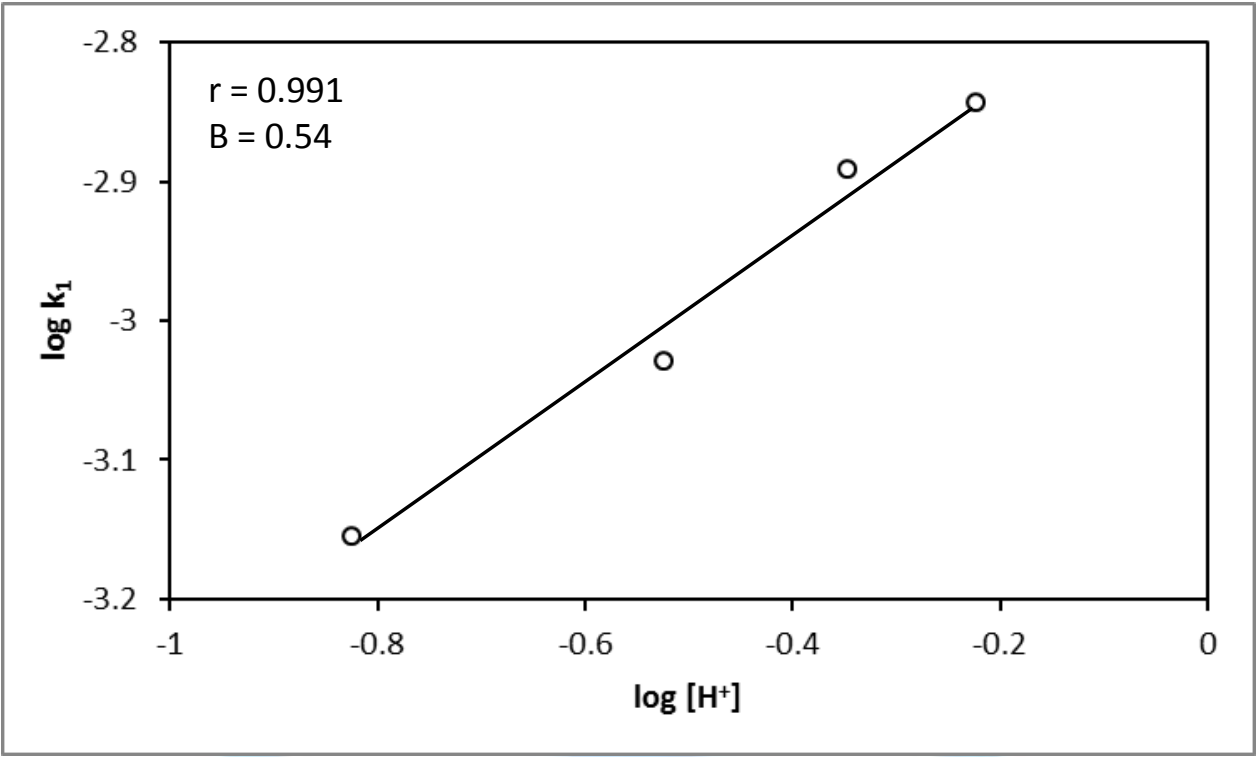

Figure 1 Plot of $\log \mathrm{k}_{1}$ against $\log \left[\mathrm{H}^{+}\right]$

Table 2. Rate Constants for the Oxidation of Benzaldehyde by QxDC at $313 \mathrm{~K}$

\begin{tabular}{|c|c|c|c|}
\hline $\begin{array}{c}\% \text { AcOH:Water } \\
(v / v)\end{array}$ & $\begin{array}{c}{\left[\mathrm{NaClO}_{4}\right] 10^{3}} \\
\mathrm{~mol} \mathrm{dm}^{-3}\end{array}$ & $\begin{array}{c}{\left[\mathrm{MnSO}_{4}\right] 10^{3}} \\
\mathrm{~mol} \mathrm{dm}^{-3}\end{array}$ & $\begin{array}{c}\mathrm{k}_{1} 10^{4} \\
s^{-1}\end{array}$ \\
\hline $70: 30$ & - & - & 9.36 \\
\hline $72: 28$ & - & - & 12.42 \\
\hline $74: 26$ & - & - & 17.22 \\
\hline $76: 24$ & - & - & 31.91 \\
\hline $78: 22$ & - & - & 56.49 \\
\hline $80: 20$ & - & - & 86.29 \\
\hline $70: 30$ & 0.00 & - & 9.36 \\
\hline $70: 30$ & 5.05 & 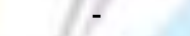 & 9.42 \\
\hline $70: 30$ & 10.10 & - & 9.31 \\
\hline $70: 30$ & 15.15 & - & 9.51 \\
\hline $70: 30$ & 20.20 & 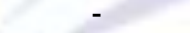 & 9.44 \\
\hline $70: 30$ & - & 0.00 & 9.36 \\
\hline $70: 30$ & - & 1.02 & 7.98 \\
\hline 70:30 & - & 2.04 & 7.12 \\
\hline $70: 30$ & - & 3.06 & 6.55 \\
\hline $70: 30$ & - & 4.08 & 6.14 \\
\hline
\end{tabular}

$\left[\mathrm{H}^{+}\right]=3.0 \times 10^{-1} \mathrm{~mol} \mathrm{dm} \mathrm{m}^{-3}$ 
Journal of Advances in Chemistry

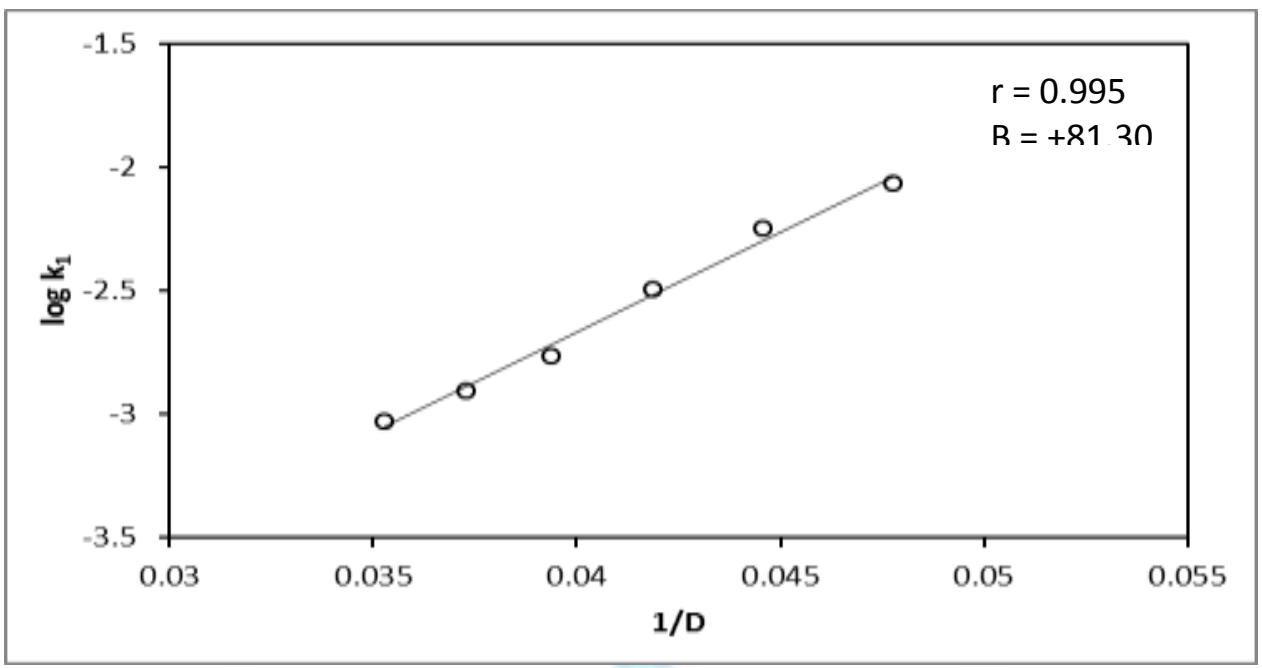

Figure 2 Plot of $\log k_{1}$ against $1 / D$

Increase in ionic strength of the medium by adding sodium perchlorate has no effect on the reaction rate indicating the involvement of charged species in the rate-determining step. The reaction mixture showing the absence of any free radical in the reaction has ruled out the possibility of a one electron transfer during the addition of acrylonitrile. But a noticeable catalytic effect on the reaction rate on the addition of $\mathrm{MnSO}_{4}$. The rate of oxidation reaction was considerably showing that the rate-determining step involves a two electron transfer in the mechanism.

The rate constants were measured at four different temperatures viz., 303, 313, 323, $333 \mathrm{~K}$, thermodynamic and activation parameters have been calculated from the plot of log $\mathrm{k}_{2} / \mathrm{T}$ against 1/T (Fig. 3) using the Eyring's equation (Table 3 ).

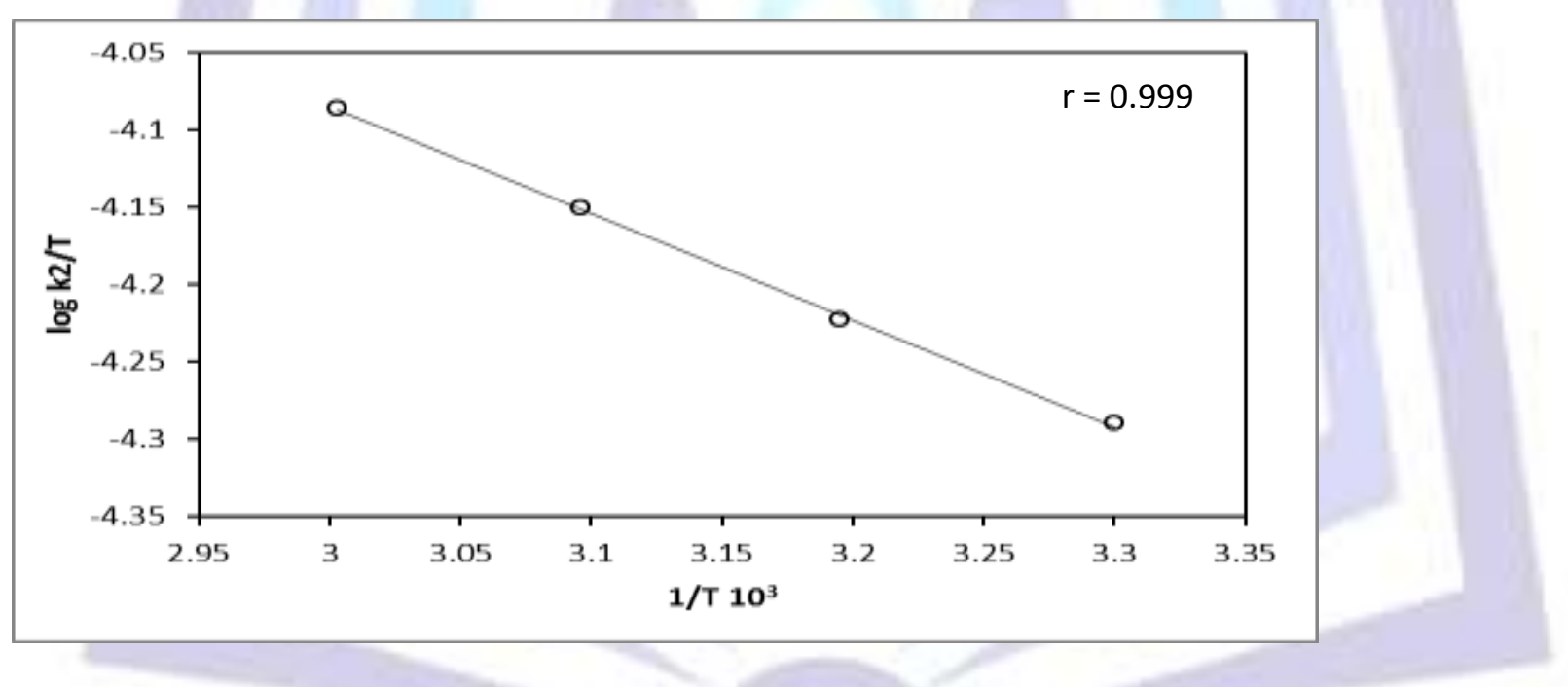

Figure 3 Plot of $\log k_{2} / T$ against $1 / T$

Table 3. Effect of Temperature for the Oxidation of Benzaldehyde by QxDC

\begin{tabular}{|c|c|l|}
\hline $\begin{array}{c}\text { Temperature } \\
\mathrm{K}\end{array}$ & $\begin{array}{c}\mathrm{k}_{1} 10^{4} \\
\mathrm{~s}^{-1}\end{array}$ & \multicolumn{1}{c|}{$\begin{array}{c}\text { Thermodynamic \& Activation } \\
\text { Parameters }\end{array}$} \\
\hline 303 & 7.77 & $\Delta \mathrm{H}^{\#}=5.75 \mathrm{~kJ} \mathrm{~mol}^{1}$ \\
\hline 313 & 9.36 & $\Delta \mathrm{S}^{\#}=-214.25 \mathrm{JK}^{-1} \mathrm{~mol}^{-1}$ \\
\hline 323 & 11.44 & $\Delta \mathrm{G}^{\#}=72.81 \mathrm{~kJ} \mathrm{~mol}^{1}$ \\
\hline 333 & 13.67 & $\mathrm{Ea}=8.35 \mathrm{~kJ} \mathrm{~mol}^{1}$ \\
\hline$[\mathrm{QxDC}]=2.0 \times 10^{-3} \mathrm{~mol} \mathrm{dm}^{-3}$ & {$\left[\right.$ Benzaldehye] $=5.0 \times 10^{-2} \mathrm{~mol} \mathrm{dm}^{-3}$}
\end{tabular}

$\left[\mathrm{H}^{+}\right]=3.0 \times 10^{-1} \mathrm{~mol} \mathrm{dm}{ }^{-3} \% \mathrm{AcOH}:$ Water $=70: 30$ 


\section{Volume ... N u m ber...}

Journal of Advances in Chemistry The reaction shows first order with respect to $\mathrm{QxDC}$, benzaldehyde and fractional order with respect to $\mathrm{H}^{+}$ion. The rate increases with increase acetic acid medium and increase in ionic strength has perceptibly changed the rate. The retardation of the rate by the addition of $\mathrm{Mn}^{2+}$ ions confirms that a two electron transfer process is involved in the reaction. Based on the above facts, the following mechanism (scheme 1) was proposed.

\section{Mechanism}

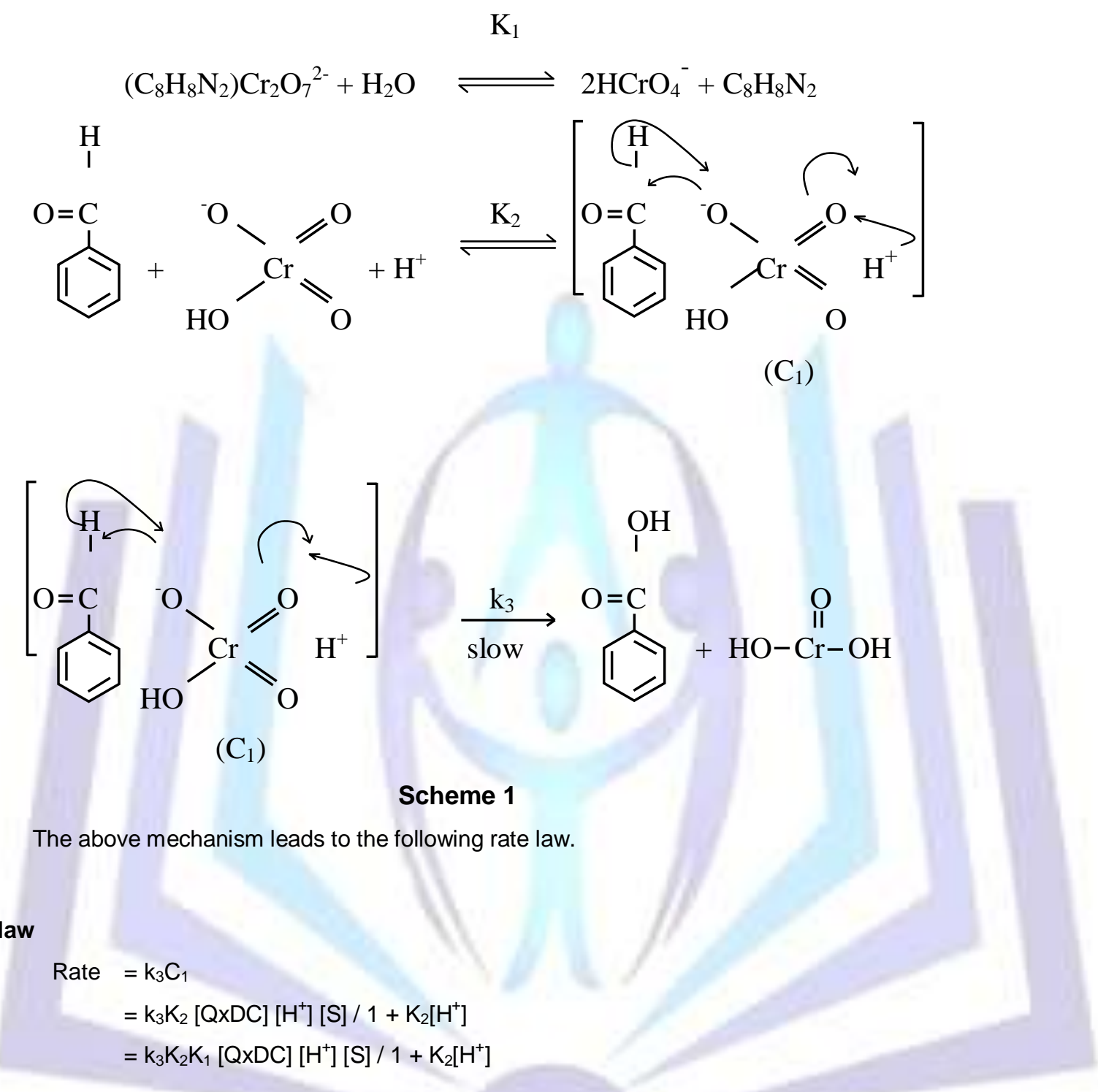

The rate law explains all the observed experimental facts.

\section{CONCLUSION}

The oxidation of benzaldehyde by quinoxalinium dichromate in aqueous acetic acid medium leads to the formation of a complex giving benzoic acid as the final product. The reactions were followed under pseudo-first order kinetics. The mechanism proposed for this oxidation kinetics in accordance with the observed kinetic data and suitable rate law was derived.

\section{REFERENCES}

[1] Degirmenbasi N and Ozgun B, Monatshefte Fur Chemie, 133, (2002), 1417.

[2] Ozgun B and Degirmenbasi N, Monatshefte Fur Chemie, 133, (2004), 483.

[3] Sekar KG and Manikandan G, Oxid. Commun., 35(3), (2012), 577.

[4] Sekar KG and Manikandan G, Int. J. Ad. Pharm. Bio. \& Chem., 1(4), (2012), 450.

[5] Sekar KG and Manikandan G, Der Chemica Sinica, 4(1), (2013), 100. 
[6] Chowdhury SK and Banerji KK, J. Org. Chem., 56(17), (1991), 5111.

[7] Ramakrishnan PS and Chockalingam P, J. Indian Chem. Soc., 70, (1993), 581.

[8] Elango KP and Karunakaran K, Asian J. Chem., 7(4), (1995), 798.

[9] Elango KP and Karunakaran K, Oxid. Commun., 19(1), (1996), 50.

[10] Abdul Jameel A, J. Indian Chem. Soc., 75, (1998), 439.

[11] Mahanti MK, Oxid. Commun., 22(1), (1999), 142.

[12] Balasubramanian K, Lakshmanan K and Sekar KG, Asian J. Chem., 11(4), (1999), 1451.

[13] Sekar KG, J. Chem. Res.(S), (2002), 626.

[14] Fatimajeyanthi G and Elango KP, Int. J. Chem. Kinet., 35, (2003), 154.

[15] Panda R and Acharya PK, Indian J. Chem., 44A, (2005), 710.

[16] Sekar KG and Prabakaran A, Oxid. Commun., 31(3), (2008), 613.

[17] Krishnasamy K, Devanathan D and Dharmaraja J, Trans. Metal Chem., 32(7), (2007), 922.

[18] Sheik Mansoor S and Syed Shafi S, E-Journal of Chem., 6(S1), (2009), S522.

[19] Kanchan Kumar Rai, Ravi Kant Kannaujia, Karuna Rai and Surjeet Singh, Orient. J. Chem., 29(3), (2013), 1071.

[20] Amis ES, J. Am. Chem. Soc., 77, (1955), 4187.

[21] Amis ES, "Solvent Effects on Reaction Rates \& Mechanism", Academic Press, Newyork, (1966), 42.

[22] Priya V, Balasubramanian M and Mathiyalagan N, J. Chem. Pharm. Res., 3(1), (2011), 522.

\section{Author' biography}

Name

Father's Name

Mother's Name

Date of Birth

Sex

Nationality

Communication

Contact number

E - Mail

Marital status

\section{Dr. K. ANBARASU}

Sri. K.N. Kaliyaperumal

Smt. K.Chitra

05.06.1980

Male

Indian

32/27A, S.P. Koil Street,

Kurinjipadi - 607 302. Tamilnadu, INDIA.

9942775940

arasu007@gmail.com

Married

Educational Qualification ～： M.Sc., Ph.D., PGDCA,

\begin{tabular}{|c|l|c|c|c|}
\hline Course & \multicolumn{1}{|c|}{ Name of the University } & $\begin{array}{c}\text { Month \& Year of } \\
\text { Completion }\end{array}$ & Percentage of Marks & Class \\
\hline Ph.D (Chemistry) & $\begin{array}{l}\text { Bharathidasan University, } \\
\text { Tiruchirappalli }\end{array}$ & September 2006 & - & Recommended \\
\hline $\begin{array}{c}\text { PGDCA } \\
\text { (Computer } \\
\text { Application) }\end{array}$ & $\begin{array}{l}\text { Bharathidasan University, } \\
\text { Tiruchirappalli }\end{array}$ & April 2005 & 78.20 & First Class \\
\hline M.Sc (Chemistry) & $\begin{array}{l}\text { Bharathidasan University, } \\
\text { Tiruchirappalli }\end{array}$ & April 2002 & 75.94 & First Class \\
\hline $\begin{array}{c}\text { B.Sc } \\
\text { (Chemistry) }\end{array}$ & $\begin{array}{l}\text { Bharathidasan University, } \\
\text { Tiruchirappalli }\end{array}$ & April 2000 & 75.12 & First Class with \\
Distinction
\end{tabular}




\section{Research Project}

Ph.D.: Kinetic Studies and Correlation Analysis on the Nicotinium Dichromate Oxidation of Phenols and Cyclanols

\section{WORKING EXPERIENCE}

As on: 11.04.2015

\begin{tabular}{|c|c|c|c|c|}
\hline SI.No. & Designation & Institution & $\begin{array}{l}\text { Handled } \\
\text { Classes }\end{array}$ & Year of Experience \\
\hline 1. & Asst. Professor & $\begin{array}{l}\text { Dhanalakshmi Srinivasan } \\
\text { Engineering College, } \\
\text { Perambalur - } 621212 .\end{array}$ & B.E. / B.Tech. & $\begin{array}{c}2 \text { years } \& 11 \text { months } \\
(04.08 .2006 \text { to } \\
30.06 .2009)\end{array}$ \\
\hline 2. & Asst. Professor & $\begin{array}{l}\text { Paavai Engineering College, } \\
\text { Namakkal - } 637018 .\end{array}$ & B.E. / B.Tech. & $\begin{array}{c}2 \text { years \&11months } \\
(01.07 .2009 \text { to } \\
08.06 .2012)\end{array}$ \\
\hline 3. & Asst. Professor & $\begin{array}{l}\text { TRP Engineering College, (SRM } \\
\text { Group), } \\
\text { Tiruchirappalli - } 621105 .\end{array}$ & B.E. & $\begin{array}{c}2 \text { year \& } 11 \text { months } \\
(28.06 .2012 \text { to } \\
04.06 .2015)\end{array}$ \\
\hline 4. & Asst. Professor & $\begin{array}{l}\text { A.A. Government Arts College, } \\
\text { Musiri - } 621211 \text {, Tamilnadu }\end{array}$ & B.Sc. / M.Sc., & 27.07.2015 to till date \\
\hline
\end{tabular}

\section{LIST OF PUBLICATIONS}

1. Oxidation of Cyclanols with Quinolinum Dichromate - A Kinetic Study

K.G. Sekar, R.R. Muthuchudarkodi and K.Anbarasu

Oxid. Commun., 30 (2), 391 (2007)

2. Structure and Reactivity of Cyclanols towards Nicotinium Dichromate Oxidation
K.G. Sekar and K.Anbarasu
Oxid. Commun., 31 (1), 199 (2008)

3. Linear Free Relationships in the Chromium (VI) Oxidation of Phenols

K.G. Sekar and K.Anbarasu

Croat. Chem. Acta., 82 (4), 819 (2009)

4. Kinetics of Oxidation of Phenoxy Acetic Acids by Nicotinium Dichromate

K.G. Sekar and K.Anbarasu

Oxid. Commun., 34 (2), 314 (2011)

5. Reactivity of $\square$-Hydroxy Acids Towards Piperidinium Chlorochromate Oxidation

K.Anbarasu and P.Selvi

Orient. J. Chem.,29(1), 247-252, (2013)

6. Oxidation of $S$-Phenylmercaptoacetic Acid by Piperidinium Chlorochromate

K.Anbarasu and P.Selvi

Chemical Sci. Trans., 2(S1), S83-S86, (2013)

7. Reactivity of $\square$-Hydroxy acids by Imidazolium Fluorochromate Oxidation

K.G. Sekar and K.Anbarasu

Oxid. Commun., 36(4), (2013) 
8. Insect Antifeedant Potent Unsaturated 1,3-Oxazine-2-Amines

G.Thirunarayanan, V.Renuga, K.G.Sekar, K. Lakshmanan and K.Anbarasu

Inter. Lett. Chem. Phy. Astra. 4, 66-81 (2014)

9. Mechanism of Glycolic Acid Towards Piperidinium Chlorochromate Oxidation

K.Anbarasu and P.Selvi

Rasayan J. Chem., 7(4), 365-369 (2014).

10. Oxidation of Glycolic acid by Piperidinium Chlorchromate

K.Anbarasu and P.Selvi

Res. J. Chem. \& Environ., 19(3), 29-33 (2015).

11. Spectral and Microbiological Study of Quinoxalinium Dichromate

K.Anbarasu and N.Geetha

Rasayan J. Chem., 8(3), 298-302 (2015). 